\section{Digital Technology, Age, and Gaming}

Neville Holmes, University of Tasmania stake" and serious games as based on video gaming but using "entertainment to further government or corporate training, education, health, public policy, and strategic communication objectives."

Mindset constitutes another dimension of gaming, one that highlights the contrast between contemplation and sensuality. Card and board games, and puzzles like sudoku and crosswords, focus on contemplative analysis. Games like tennis and football focus on per-

\section{Things are not} as they were, particularly in play. ing that revealed how marketing people view the field. I felt that computing professionals would see it somewhat differently, but that it wasn't worth arguing about. Then I stumbled on an interview in The Guardian of September 19, 2005 (http://www. guardian.co.uk/g2/story/0,,1573071, 00.html) where Edward Castronova, an economist, alarmingly claimed that "Computer gaming is so powerful a tool we could use it to meet our emotional needs and even spread democracy." Though, like Alfred Nobel, I have always been very skeptical about economics as a science, the few economists I know seem to be quite reasonable people. But this apparently unreasonable economist has crossed over into our field and written a book on computer gaming.

Then the September Computer issue arrived with Michael Zyda's “From Visual Simulation to Virtual Reality to Games" (pp. 25-32). This splendid article, both interesting and informative, left me with the feeling that a severe generation gap separates Zyda and me, and that in our differences lie several issues of particular importance to the computing profession.

The report in The Economist stated early on that "three important factors are generally overlooked: that attitudes to gaming are marked by a generational

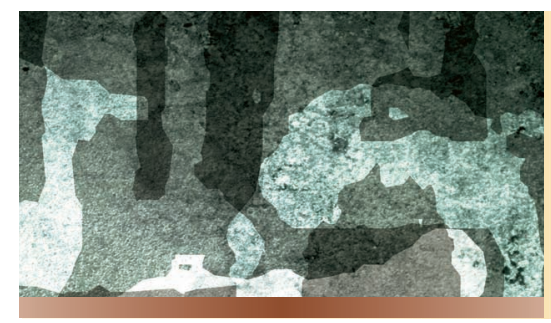

divide; that there is no convincing evidence that games make people violent; and that games have great potential in education." At least two of these factors seemed to me to be anything but overlooked, and two of them are misconstrued. Before looking at these factors in turn, though, it is helpful to define what kinds of gaming there are.

\section{GAMING AND PLAY}

The terms gaming and play largely overlap nowadays, but gaming used to mean gambling, that is, an activity in which a bettor stakes money. Gambling has been greatly extended by digital technology, through geographical dispersion by telecommunication as in lotteries or keno and financial markets, by machinery running the gambling as in poker machines, and by credit card systems providing players with easy finance. The converse of gambling is sport, in the sense of active participation, though games can have an element of both.

Video games and computer games seem to differ only in the physical equipment used to play them. Zyda contrasts video games as "played for amusement, recreation, or winning a ception and reaction. Analytical gamers try to get correct answers, or at least better ones than their opponents, while physical gamers try to apply physical skill or strength, often where speed is an advantage. Computer games like Minesweeper are contemplative, whereas games like Tetris are predominantly sensual.

Solitary games involve one player only, while social games involve more than one. Traditionally, most computer-free games have been social, most computer games solitary. Although this might seem a binary classification, the Internet has bred two hybrids:

- normally social games such as bridge played by isolated players, and

- video games played by many players.

Neither of these is truly social: online bridge takes place outside a social context, while the multiplayer video game offers a social context that is artificial in both its nature and its participants.

Subject matter provides video games' remaining aspect. For example, in Continued on page 106 
Secrets of the PlayStation2 (ibooks, inc., 2000), Michele Davis classifies video games along two dimensions:

- Ratings. These range from early childhood through all ages, teen, mature, and adults only.

- Theme. These break down into the following game genres: action, adventure or horror, arcade, classic and puzzle, driving and vehicular combat, fighting, role-playing, simulation, sports, and strategy.

\section{THE GENERATIONAL DIVIDE}

The Economist report states that "Games are, in fact, played mainly by young adults. Only a third of gamers are under 18." In the same article, Marc Prensky of Games2train claims that not-so-young adults, never having played them, don't understand "that these are complex games, which take 30, 40, or 100 hours to complete." What Prensky and many others don't understand is that to many adults, particularly old ones like me, having to spend anything like that amount of time in total surrender to someone else's imagination is a thorough turnoff.

But to describe this gap in appreciation as generational is misleading. It is cultural, not necessarily correlated with age, and somewhat related to gaming's mindset dimension.

Old people like myself grew up before television, when recreation in the home occurred socially through playing board and table games and participating in mealtime conversations, or personally through reading. This contemplative culture emphasized learning how to play and discuss well and how to understand people in other societies and circumstances.

Today's youth culture emphasizes the sensual. Watching and listening to television, or immersion in video games, dominates recreation. These activities commandeer perception and channel thought.

When you read a book, you construct mental images of people and places, follow and interpret sequences of actions and events, and develop feelings about the personalities and behaviors. When you watch a movie or television show, you are presented with the images of people and places, you mostly just observe the actions and events because there isn't time to think much about them, and the feelings you develop are strongly influenced by your direct observation of the actors' behavior-or by canned laughter.

\section{Marketing people now see the Internet and video games as extending and perhaps supplanting commercial television.}

Although people like me prefer the contemplative culture, many others seem to prefer the sensual. This is a matter of upbringing, not simply of age, and not a matter of one culture being right and the other wrong. So it's my culture that makes me strongly prefer Minesweeper to Grand Theft Auto, not my lack of video game expertise.

\section{THE TENDENCY TO VIOLENCE}

The report in The Economist builds a case for refuting the idea that video gaming induces violent behavior and includes a graph that shows violent crime in the US declining steadily over the past decade. It also outlines an experiment in which the group that had to play a violent video game for two hours daily for a month showed a frequency of aggressive behavior similar to the control group. I didn't find this refutation convincing because it's possible to explain the results in other ways.

Everyday experience does suggest an increase in violence and aggression. While I was writing this essay, a local man in my small provincial city was sent to jail for driving his car onto the sidewalk to knock down a pedestrian whom he then drove over to ensure his death. The pedestrian was unknown to the driver, who did it, he said, because "it seemed funny at the time."

About the same time, the media reported the failure of an appeal against the conviction of a man for murdering a motorcyclist in a fit of road rage. On that same day, researchers released the results of a study that showed that 44 percent of Australia's drivers had experienced road rage, up from 22 percent in 1996 , and that 82 percent of them believed their rage to be justified.

But concentrating on the symptom of violence ignores its cause, which is arguably the shift to a sensual culture. A sensual culture encourages uncontemplative reaction to stimulus. Road rage is simply one kind of uncontemplative reaction.

Commercial television's whole point is to promote the uncontemplative buying reaction a consumer society depends on for economic growth. Marketing people now see the Internet and video games as extending and perhaps supplanting commercial television. Thus, advertisements increasingly add their clutter to Web browsing, along with brand placement in video games.

\section{THE POTENTIAL FOR EDUCATION}

The unpleasant consequences of this dominance of the sensual raise the need for a rational balancing of the contemplative and sensual culturesa task that could take generations of systematic and intense education to achieve.

Zyda commendably supports the adaptation of video gaming to training and education by having a human-performance-engineering team interact with game developers. Given that Zyda's aim for these serious games is to "engage the game player's mind via sensory stimulation and providing methods for increasing the sense of presence which contribute to building a feeling of immersion," his approach clearly lies deeply in the sensual culture, and it is an excellent one for the inculcation of high-level reflex skills. But it will be at least as effective in forc- 
ing the uncontemplative absorption of dogmata, which can be socially dangerous.

This is not a theoretical danger. As The Economist points out, in Sim City, a video game widely recommended for school use, "the player assumes the role of a city mayor, [and learns that] no amount of spending on healthcare is ever enough to satisfy patients, and the fastest route to prosperity is to cut taxes." Dogma indeed!

Educators adopted an older approach, academic gaming, for traditional business games in which a market is modeled for teams of players forming the companies active in that market. Each team makes decisions quarterly. The simulation is fed the decisions quarter by quarter and produces documents that describe the results.

Two kinds of skills are learnt in these business games: the understanding and use of accounts and balance sheets and the social negotiation needed to make joint decisions within a team.

Academic gaming can be extended beyond business to many fields and skills at many levels. It provides the social and contemplative counterpart of sensual video gaming. It also has the potential to be extremely valuable in schools, as I outlined in "The Myth of the Educational Computer" (Computer, Sept. 1999, pp. 36-42). Academic gaming has not taken off in schools, possibly because teachers need special training to exploit the technique and this has not yet been accepted by those who teach teachers.

About 30 years ago, I attended a conference of the Society for Academic Gaming and Simulation in Education and Training in Loughborough, U.K., where highly competent people expressed great enthusiasm for the potential role of academic games in schools. They surely deserved success more than their near oblivion.

For some time there has been an international federation of similar societies, the International Simulation and Gaming Association (www.isaga.info). These societies lack prominence, how- ever, and at least one seems to be defunct. Nonetheless, they deserve the strong support of the computing profession.

Academic games suffer from the problem of relying on their players having basic knowledge and skills, but students nowadays do not develop these attributes sufficiently. Basic knowledge or vocabulary and basic skills such as reading, spelling, and arithmetic are ideally suited to being imparted by drill and practice using simple video gaming techniques. This kind of instruction doesn't require immersion. Schooling would be tremendously helped by the development of simple machines to deliver drill and practice, provided teachers could be trained in their use.

Drill and practice also have value outside early schooling. I can't help feeling that, given the nature of the conflict in Iraq, the soldiers there would have been better off if video gaming had been used to drill them in reading and speaking Arabic. With modern voice-processing technology such drill could be made very effective.
$\mathbf{T}$ he development of basic skills has particular significance for the computing profession, and indeed for engineering and science generally. Fewer young people study mathematics and science at school, and universities are closing down some important technical areas. The number of engineering graduates in many advanced countries declines steadily, forcing industry to rely increasingly on importing professional skills from countries where contemplative culture still dominates. This situation can only be countered by emphasizing the development of basic skills in early schooling. This could be achieved far more effectively with gaming technology than with the classroom chanting used when I attended primary school.

Neville Holmes is an honorary research associate at the University of Tasmania's School of Computing. Contact himatneville.holmes@utas.edu.au. Details of citations in this essay, and links to further material, are at www. comp.utas.edu.au/users/nholmes/prfsn.

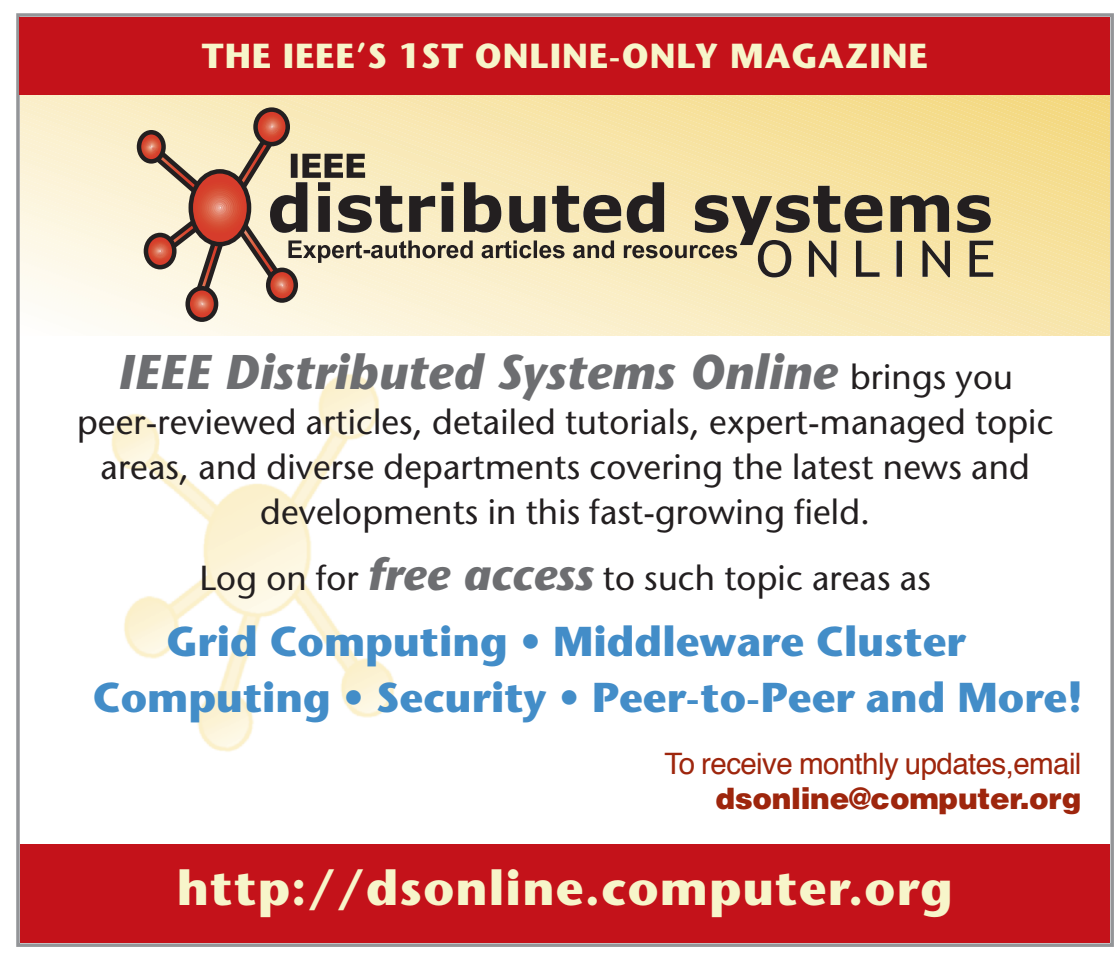

